Editorial

Pensar en Movimiento:

Revista de Ciencias del Ejercicio y la Salud

EISSN 1659-4436

Vol. 12, No.2, pp. 10- 17

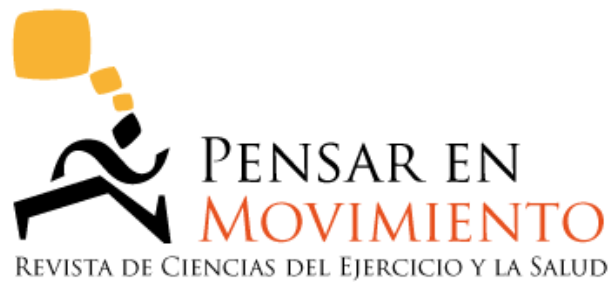

\title{
MULTILINGUAL PUBLICATION AS A LEGITIMATE TOOL TO INCREASE ACCESS TO SCIENCE (English translated version) $^{1}$
}

\author{
Luis Fernando Aragón Vargas, Ph.D.; FACSM \\ LUIS.ARAGON@ucr.ac.cr \\ Escuela de Educación Física y Deportes, Universidad de Costa Rica, Costa Rica
}

Published: $12 / 12 / 2014$

doi: http://dx.doi.org/10.15517/pensarmov.v12i2.17584

\begin{abstract}
Aragón-Vargas, L.F. (2014). Multilingual publication as a legitimate tool to increase access to science. Pensar en Movimiento: Revista de Ciencias del Ejercicio y la Salud, 12 (2), 10-17. Duplicate publication, including the submission or publication of the same manuscript in two or more languages, is considered scientific misconduct. Meanwhile, properly conducted multilingual publication has been an exception difficult to deal with, rather than part of the normal scientific publishing process. While publication of a manuscript in a second or third language should not receive the same credit as the original publication, it should not be punished. Provided the appropriate disclosures and preliminary steps are taken, it should be highly encouraged instead, as it will enhance scientific communication and may reduce the knowledge gap around the world. Different types of multilingual publications are summarized and some basic guidelines are offered for the sanctioned publication of the same paper in multiple languages.
\end{abstract}

Keywords: redundant publication, ethics in science, publication ethics, translation

According to the International Committee of Medical Journal Editors (ICMJE), submission of "the same manuscript, in the same or different languages, simultaneously to more than one journal" is considered scientific misconduct (International Committee of Medical Journal Editors, 2014). There are good, sound reasons for this policy, but I would like to present a rationale and some necessarily preliminary guidelines for scientific journal editors for the publication of the same manuscript in two or more languages, a practice which could improve science communication and should not be considered scientific misconduct. This paper was inspired by an Editorial by Zhang (Zhang, 2013).

\footnotetext{
${ }^{1}$ Also available in Spanish and Portuguese in this same journal
} 
A major argument for multilingual publication is the fact that science from secondary countries needs to be more visible. Several papers have discussed hidden or "lost" science: valuable research in secondary languages such as Spanish or Portuguese which is commonly ignored in systematic reviews and not even read by scientists (Gibbs, 1995; Stolerman \& Stenius, 2008; Williams, Bórquez, \& Basáñez, 2008). Although English is the major language for scientific communication, knowledge should have no single language.

\section{Bilingual publication}

Multilingual publication of scientific papers takes different forms. For instance, the same paper may be published in two or more languages in the same journal, but there are no clear guidelines to do so. Some journals have published one single article (with one single digital object identification-DOI) in two languages, side-by-side in the same electronic file or printed copy (cf. Jeukendrup, 2013). This can be called a bilingual publication, but it has limitations because the secondary language is not visible to search engines and the DOI leads to the primary language information only. Because of these limitations, readers who might benefit the most from the availability of the information in their own language may not be aware of its existence. In addition, while citation may be considered straightforward, there is no complete transparency, as the language version used in the submission and review process is not usually revealed and does not necessarily match the primary language of the journal.

\section{Simultaneous multilingual publication}

Other journals make the same article available in two or more languages, simultaneously but as separate electronic files, using the same DOI (cf. Angelo, Leite, \& Castilho, 2011), hereby called simultaneous multilingual publication. The service is very useful to readers who know where to look, but again, it may not be visible to search engines. Using a single DOI is optional; the choice is surprising since major journal manager software such as Open Journals System assign separate URLs to the different language versions of the same paper, and CrossRef provides a way for using a separate DOI for each language (CrossRef, 2014).

Simultaneous multilingual publication is poised to play a very important role in scientific communication, as recently suggested by Salager-Meyer (2014). Currently, in recognition of the quality of the work being performed by non-English speaking scientists, many of the larger journals offer professional translation services (for a fee), to enable them to publish in English. When these authors choose to do so instead of using their own language, they are in practice shutting out many of their colleagues who will not have access to the information. This restriction to information can be as relevant as that previously imposed by subscription-only journals, a serious limitation being overcome thanks to the Open Access movement, with its short embargoes, mandatory deposit in public repositories, and other changes in the publishing model. 
Simultaneous multilingual publication is highly desirable because it addresses the population that often times provided the funds and even the study participants. It also makes scientific information promptly available to local or regional scientists in their native language, while meeting the needs of the authors to make their work visible to the rest of the world.

When a journal chooses to publish the same manuscript in two or more languages, it is providing a very important service while avoiding most -if not all- of the problems caused by duplicate publications, as listed by Alfonso et al. (Alfonso, Bermejo, \& Segovia, 2005). Only one review process is performed, there is transparency, and the journal can decide if it has the space and resources available to do it without harm to the conventional articles. Current practice is, however, open to several important improvements. First, both bilingual publications and simultaneous multilingual publications should include a disclosure, probably next to the manuscript submission date, of the language used for submission and review. Second, a better system needs to be implemented to allow for distinct citation of each language version, as there will always be differences which may create confusion; citation of the version actually read by the authors is recommended. Third, to make the secondary language versions visible and widely accessible, separate digital object identification and/or indexing is desirable, following the instructions from CrossRef (2014). The fact that the paper is available in other languages should be explicitly stated on the first page and in the metadata.

\section{Translation of previously published papers}

A separate modality is the translation of a published paper into two or more languages in different journals. Hereby called sequential multilingual publication, it is considered desirable by the International Committee of Medical Journal Editors (2014) if the goal is to reach the widest possible audience with relevant information. Many journals have translated and published policies or consensus statements from different world-class organizations (cf. Alfonso et al., 2005), but only recently have guidelines been published on how to publish papers in secondary languages (International Committee of Medical Journal Editors, 2014) or translations into English (The European Association of Science Editors, 2014); the latter are more of a technical nature and do not refer specifically to previously published manuscripts.

Organizations such as the American College of Sports Medicine have commissioned the official translation of their position stands into different languages (cf. American College of Sports Medicine, 2014), but the resulting documents are usually not published in scientific journals and are typically only visible to members of the organization or visitors of their website. They are considered a service to visitors, not publications. While formal, timely publication of this type of papers would be highly desirable, there should be a previously agreed interval between the original publication and the secondary one, to grant priority to the former (International Committee of Medical Journal Editors, 2014). 
The intellectual work involved in these translations is usually not balanced by the credit obtained, which raises an interesting question about authorship: if a translated (secondary) paper gets published, should the authors be the same as in the original one, or is the scientist who translated the paper, with the appropriate disclosures and permissions, the author of the secondary work? The answer is not as obvious as it seems, because some or all of the original authors may be reluctant to assume responsibility for a paper in a language they do not understand! There are additional matters to be considered: the journal editor for the secondary publication may consider it unnecessary to perform a conventional double-blind peer review, or she/he may decide to hire a professional to assure translation accuracy. These and other issues vary depending on the language order in the publication sequence.

Publication of English papers translated into secondary languages is not uncommon. As an example from exercise science, Editorial Biosystem from Argentina published professionally translated, full versions of original research papers at least since 1997, in an effort to make the original work available to Spanish-speaking scientists and professionals. Authors and publishers of the original work in English are encouraged to grant the appropriate permissions for this type of effort, as the secondary language publication will reach a different audience, increasing dissemination of knowledge and hence making it more universal, in line with Salager-Meyer's recommendations for improving the quality of science in what he calls the periphery (Salager-Meyer, 2008).

On the other hand, mainstream journals may be willing to consider publication of English translations of papers already published in other languages, but this is highly unlikely. The model will be more suspect of duplicate publication, and the authors will need to justify why the submission was not in English to begin with. This is unfortunate, as many people around the world share the experience of Professor Gilson Volpato (an authority on scientific publication in Brazil) who points out the value of multilingual publication for nonscientists and practitioners. He says: "I learned about some interesting work from Japanese researchers because an Israeli translated it into English, in 1977" (personal communication, 2014). Regardless, under the current model, no mainstream journal will want to consider a secondary publication. This opens an important opportunity to periphery journals which, in addition to providing all metadata and abstracts in English, should implement multilingual simultaneous publication of full manuscripts. These journals may also consider publication of manuscripts previously published in their primary language, as secondary publications translated into English.

\section{Transparency, compliance, and pending issues}

The legitimate publication of a translated paper must not only strictly follow intellectual property law, but it should also meet pre-established criteria for the sake of transparency, especially in the case of sequential publication: permissions must be obtained in writing from the publisher and all authors of the original article; the nature of the translated article must be disclosed upon submission to the secondary journal; the author should explain the rationale for the translation in the body of the article; the journal 
should highlight relevant information in the article title and metadata; the original article must be properly cited (International Committee of Medical Journal Editors, 2014; Zhang, 2013).

An important issue that remains to be worked out is the handling of academic merit: because it is not original work, a secondary (translated) publication should not be counted, or should have very different weight (it does make an important contribution to the body of knowledge in the secondary language), when quantitative evaluations are made for specific authors or institutions (Zhang, 2013). This will require specific policies and algorithms to be developed, but the elements of transparency in the previous paragraph will aid in their implementation.

Final comments

Readers are encouraged to consider the present article as an example: if published only in English, secondary language authors would not easily find out about these important publication tendencies which may have a direct impact on their work. On the other hand, if published only in Spanish or Portuguese, the editors from most primary journals would remain oblivious to the discussion. We trust that this editorial will encourage more periphery journals to include multilingual publication. Furthermore; authors are invited to translate this editorial, respecting its Attribution license, into other secondary languages.

Until recently, multilingual publication has been an exception difficult to deal with, rather than part of the normal scientific publishing process. While publication in two or more languages should not be given the same weight as the original publication, it should not be punished. Provided the appropriate disclosures and preliminary steps are taken, it should be highly encouraged instead, as it will enhance scientific communication and may reduce the knowledge gap around the world. An attempt has been made to classify the different multilingual publication types (see Table 1), and a few recommendations have been presented to serve as a working document for the publication of needed guidelines. 


\section{Table 1.}

Proposed classification of redundant publication processes in two or more languages.

\begin{tabular}{|c|c|c|c|c|}
\hline & ICMJE $^{\mathrm{a}}$ & Springer $^{b}$ & Elsevier $^{\mathrm{C}}$ & Comments/recommendation \\
\hline Duplicate submission. & $\begin{array}{ll}\text { Condemned. } & \text { Multiple } \\
\text { languages explicitly not an } \\
\text { exception. }\end{array}$ & $\begin{array}{l}\text { Condemned. } \\
\text { languages not } \\
\text { mentioned. }\end{array}$ & $\begin{array}{llr}\text { Condemned. } & & \text { Multiple } \\
\text { languages not } & \text { explicitly } \\
\text { mentioned. } & & \end{array}$ & $\begin{array}{l}\text { Unquestionably scientific } \\
\text { misconduct. } \\
\text { Unjustifiable. }\end{array}$ \\
\hline Duplicate publication. & $\begin{array}{l}\text { Condemned. Multiple } \\
\text { languages presented as a } \\
\text { separate category (see } \\
\text { Secondary Publications). }\end{array}$ & $\begin{array}{l}\text { Condemned, except } \text { when } \\
\text { proper permission } \\
\text { notification exist. }\end{array}$ & $\begin{array}{l}\text { Condemned. Multiple } \\
\text { languages discussed under } \\
\text { duplicate submission below. }\end{array}$ & $\begin{array}{l}\text { Scientific misconduct. } \\
\text { Must be avoided by following } \\
\text { clearly established criteria. }\end{array}$ \\
\hline $\begin{array}{l}\text { Bilingual publication } \\
\text { (Refers to the single } \\
\text { publication of a paper in two } \\
\text { languages, side by side on } \\
\text { the same page). }\end{array}$ & Not mentioned. & Not mentioned. & Not mentioned. & $\begin{array}{l}\text { Clearly NOT scientific } \\
\text { misconduct. } \\
\text { Only one language will be } \\
\text { visible to search engines and } \\
\text { accessed from the DOI. }\end{array}$ \\
\hline $\begin{array}{l}\text { Sequential multilingual } \\
\text { publication } \\
\text { (Refers to the publication of } \\
\text { one paper in two or more } \\
\text { languages in different } \\
\text { journals). }\end{array}$ & $\begin{array}{l}\text { Acceptable as Secondary } \\
\text { Publications. Considered } \\
\text { justifiable and beneficial, } \\
\text { particularly if the goal is to } \\
\text { reach the widest possible } \\
\text { audience with relevant } \\
\text { information. Subject to } \\
\text { meeting conditions }\left(\text { see }^{\mathrm{a}} \text { ). }\right.\end{array}$ & $\begin{array}{l}\text { Open possibility with proper } \\
\text { permission or notification. } \\
\text { Not explicitly encouraged. }\end{array}$ & $\begin{array}{l}\text { Optional, but following clearly } \\
\text { stated requirements from the } \\
\text { time of submission (see c). } \\
\text { Not explicitly encouraged. }\end{array}$ & $\begin{array}{l}\text { Encouraged, especially from } \\
\text { primary to secondary } \\
\text { languages. } \\
\text { required. Separate indexing } \\
\text { recommended (currently not } \\
\text { the case in PUBMED). } \\
\text { Separate DOI not } \\
\text { questionable. }\end{array}$ \\
\hline $\begin{array}{l}\text { Simultaneous multilingual } \\
\text { publication } \\
\text { (Refers to the publication of a } \\
\text { paper in two or more } \\
\text { languages as separate files in } \\
\text { the same journal). }\end{array}$ & $\begin{array}{l}\text { An example is briefly } \\
\text { mentioned with some special } \\
\text { characteristics. }\end{array}$ & Not mentioned. & Not mentioned. & $\begin{array}{l}\text { Encouraged. } \\
\text { Transparency required. } \\
\text { Separate PUBMED indexing } \\
\text { recommended (currently not } \\
\text { the case). } \\
\text { A separate DOI is desirable } \\
\text { for each version to improve } \\
\text { visibility and correct citation. }\end{array}$ \\
\hline
\end{tabular}

adapted from "Overlapping publications" por International Committee of Medical Journal Editors, 2014.

b Adapted from "Publishing ethics for journals. A guide for Editors-in-Chief, Associate and Managing editors" por Springer, n.d.

C Adapted from "Identify 3. What identifies a case in this area?" por Elsevier, 2014. 


\section{References}

American College Sports Medicine. (2014). Translated Position Stands. Retrieved from: http://www.acsm.org/about-acsm/international-outreach/translated-position-stands

Alfonso, F., Bermejo, J., \& Segovia, J. (May, 2005). Duplicate or Redundant Publication: Can We Afford It? Revista Española de Cardiología (English Edition), 58(5), 601604. doi: http://dx.doi.org/10.1016/S1885-5857(06)60739-1

Angelo, M., Leite, M. M. J., \& Castilho, V. (2011). Journal networking in nursing: a challenge to be shared. Revista Da Escola de Enfermagem Da USP, 45(6), 12791280. doi: http://dx.doi.org/10.1590/S0080-62342011000600001

CrossRef. (n.d.). Assigning DOIs to translations. Retrieved from: http://help.crossref.org/translations

Elsevier. (2014). Identify 3. What identifies a case in this area? Retrieved from: http://www.elsevier.com/editors/perk/multiple,-duplicate,-concurrentpublicationsimultaneous-submission/identify-3

Gibbs, W. (August, 1995). Lost Science in the Third World. Scientific American, 273, 9299. Retrieved from: http://www.scientificamerican.com/article/lost-science-in-thethird-world/

International Committee of Medical Journal Editors. (2014). Overlapping publications. Retrieved from: http://www.icmje.org/recommendations/browse/publishing-andeditorial-issues/overlapping-publications.html

Jeukendrup, A. (2013). Los carbohidratos durante el ejercicio: la investigación de los últimos 10 años. Nuevas recomendaciones. Apunts, (113), 7-22. doi: http://dx.doi.org/10.5672/apunts.2014-0983.es.(2013/3).113.00

Salager-Meyer, F. (2008). Scientific publishing in developing countries: Challenges for the future. Journal of English for Academic Purposes, 7(2), 121-132. doi: http://dx.doi.org/10.1016/j.jeap.2008.03.009

Salager-Meyer, F. (2014). Writing and publishing in peripheral scholarly journals: How to enhance the global influence of multilingual scholars? Journal of English for Academic Purposes, 13, 78-82. doi: http://dx.doi.org/10.1016/j.jeap.2013.11.003

Stolerman, I. P., \& Stenius, K. (January, 2008). The language barrier and institutional provincialism in science. Drug and Alcohol Dependence, 92(1-2), 1-2. doi: http://dx.doi.org/10.1016/j.drugalcdep.2007.07.010

Springer. (n.d.). Publishing Ethics for Journals. A guide for Editors-in-Chief, Associate and Managing editors. Retrieved from: http://www.springer.com/gp/authorseditors/editors\#c4176 
The European Association of Science Editors. (2014). EASE Guidelines for Authors and Translators of Scientific Articles to be Published in English. Retrieved from: http://www.ease.org.uk/publications/author-guidelines

Williams, J. R., Bórquez, A., \& Basáñez, M.-G. (2008). Hispanic Latin America, Spain and the Spanish-speaking Caribbean: A rich source of reference material for public health, epidemiology and tropical medicine. Emerging Themes in Epidemiology, 5(1), 17. doi: http://dx.doi.org/10.1186/1742-7622-5-17

Zhang, Y. (2013). Bilingual (multilingual) publications and duplicate publications: for or against? Journal of Zhejiang University-SCIENCE A, 14(9), 687-690. doi: http://dx.doi.org/10.1631/izus.A1300272 